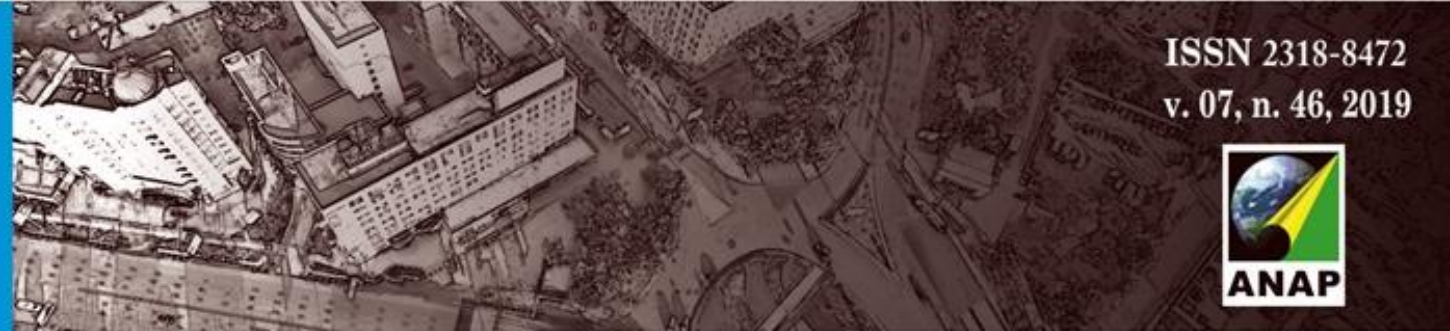

Revista Nacional de

Gerenciamento de Cidades

\title{
Narrativas Urbanas: Centros Antigos e Sociedade Civil. Os Casos de Portimão e Loulé, Algarve, Portugal
}

Urban Narratives: Ancient Centers and Communities. The Cases of Portimão and Loulé, Algarve, Portugal

Narrativas Urbanas: Centros Antiguos y Comunidades. Portimao El Caso Y Loulé, Algarve, Portugal

Lucinda Oliveira Caetano

Investigadora CIAUD, Universidade de Lisboa, Portugal

lucinda.caetano63@gmail.com

José Crespo

Professor Doutor, Universidade de Lisboa, Portugal jcrespo@fa.utl.pt

Rodrigo Cury Paraízo Professor Doutor, UFRJ, Brasil rparaizo@gmail.com 


\section{RESUMO}

Trata o presente trabalho da narrativa territorial e temporal comparativa de duas cidades - Portimão e Loulé - na sua relação com a região onde estão inseridas, a do Algarve. A função e a topografia que presidiram aos assentamentos humanos no Algarve - região sul de Portugal - determinaram uma ocupação do território em duas linhas paralelas, uma junto ao mar - cidades ribeirinhas - e outra mais interior - cidades colinas - tendo sofrido mudanças temporais distintas, apresentando atualmente especificidades próprias. Nesse contexto, os centros urbanos antigos, repositórios de identidades e memórias coletivas, são o laboratório urbano ideal para a análise dessas distinções e das mutações culturais e humanas que a materialização das diferentes políticas urbanas determinou. Nesta narrativa urbana do tempo longo, tentaremos perceber em que medida as populações se foram moldando; as cidades foram ganhando ou perdendo vitalidade; e as populações se foram identificando ou não com o sítio. Para corroborar ou refutar as conclusões retiradas da análise histórico-cultural, no que concerne ao sentimento de pertença das populações, recorre-se a inquéritos por questionário, realizados nas duas cidades, selecionando qualitativamente alguns atores-chave dessas sociedades. Os resultados desta sub-investigação demonstram que quanto mais aceleradas são as mudanças e quanto menor for o envolvimento das populações nas políticas urbanas, mais "anônimos" se tornam os centros antigos e menos identificação existe com as populações locais.

PALAVRAS-CHAVE: Narrativas urbanas, centros antigos, sociedade civil

\section{ABSTRACT}

The present work deals with the comparative territorial and temporal narrative of two cities - Portimão and Loulé - in their relationship with the region where they are inserted, the Algarve. The function and the topography that presided over the human settlements in the Algarve - southern region of Portugal - determined an occupation of the territory in two parallel lines, one by the sea - riverside cities - and another more inland - hill cities - having undergone different temporal changes, currently presenting their own specificities. In this context, the old urban centers, repositories of identities and collective memories are the ideal urban laboratory for the analysis of these distinctions and the cultural and human mutations that the materialization of the different urban policies have determined. In this urban narrative of the long time we will try to understand to what extent the populations have been shaping; the cities were gaining or losing vitality and the communities were identifying themselves or not with the site. In order to corroborate or refute the conclusions drawn from the historical-cultural analysis regarding the sense of belonging of the communities, we will resort to questionnaire surveys conducted in the two cities with qualitatively selected key actors of these communities. The results of this sub-research show that the faster the changes are and the less population involvement in urban policies, the more "anonymous" the old centers become and the less identification there is with the local communities.

KEY-WORDS: Urban Narratives, Ancient centers, Communities

\section{RESUMEN}

El presente trabajo trata de la narrativa territorial y temporal comparativa de dos ciudades - Portimão y Loulé - en su relación con la región donde están insertadas, la del Algarve. La función y la topografía, que rige los asentamientos humanos en el Algarve - la región sur de Portugal - determinaron una ocupación del territorio en dos líneas paralelas, uno al lado del mar - ciudades junto al río - y otro más en el interior - ciudades colinas - ha sido objeto de varios cambios en el tiempo, presentando actualmente especificidades propias. En este contexto, los centros urbanos antiguos, repositorios de identidades y memorias colectivas (FERNANDES, 2014), son el laboratorio urbano ideal para el análisis de esas distinciones y de las mutaciones culturales y humanas que la materialización de las diferentes políticas urbanas ha determinado. En esta narrativa urbana del tiempo largo (BRAUDEL, 1978), intentaremos percibir en qué medida las poblaciones se fueron moldeando; las ciudades fueron ganando o perdiendo vitalidad y las comunidades se fueron identificando o no con el sitio. Para corroborar o refutar las conclusiones extraídas del análisis histórico-cultural en lo que concierne al sentimiento de pertenencia de las comunidades, recurrirá a encuestas por cuestionario realizadas en las dos ciudades cualitativamente por la selección de actores clave de esas comunidades. Los resultados de esta sub-investigación demuestran que cuanto más acelerados son los cambios y cuanto menor es la participación de las poblaciones en las políticas urbanas, más "anónimos" se convierten en los centros antiguos y menos identificación existe con las comunidades locales.

PALABRAS CLAVE: Narraciones urbanas, Centros antiguos, Comunidades 


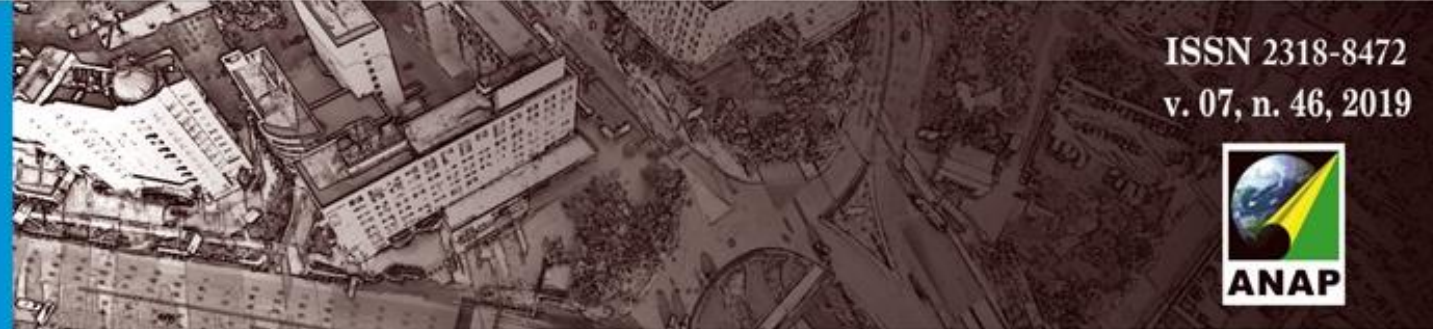

Revista Nacional de

Gerenciamento de Cidades

A cidade, como se encontra na história, é o ponto de máxima concentração de poder e cultura de uma comunidade.

Lewis Mumford (1982)

No passado, as ruas e os locais públicos eram palcos onde classes sociais e usos sociais mesclados, estágios solenes, cerimônia $e$ espetáculo improvisado, de observação de pessoas, de recreação. (T.A.)

Spiro Kostof (1989)

\section{INTRODUÇÃO}

O presente trabalho pretende analisar o contexto territorial na sua "viagem temporal", do tempo longo (BRAUDEL, 1978), e simultaneamente a conjuntura sócio-política-económica dos casos de estudo, da investigação-ação de doutoramento, referente ao desenvolvimento de modelos de gestão participados para a regeneração urbana dos centros antigos.

Como refere Sérgio Fernandes, o "código genético" identitário de um "assentamento humano" encontra-se na sua forma urbana e, para entendê-lo importa "compreender o traçado urbano a partir da morfogénese, ou seja, do reconhecimento das causas e condicionantes que estão na origem e determinam uma forma, e da capacidade geradora e persistente dessa matriz na formação do traçado ao longo do tempo" $(2014$, p.6).

Contudo, uma análise urbana global não se esgota na forma urbana, nem sequer nos elementos da cultura material e imaterial que subsistiram no tempo e são reflexo do percurso histórico dos aglomerados urbanos. É importante observar também as várias conjunturas sócio-políticoeconômicas que os aglomerados urbanos sofreram até chegarem aos nossos dias, incluindo a materialização das políticas urbanas mais recentes para compreender a cidade atual.

Apesar de parecer evidente que a vitalidade urbana (COSTA e LOPES, 2012) ${ }^{1}$ da "cidade construída" se constitui como um reflexo de políticas urbanas potenciadoras de atratividade para os centros antigos, julga-se que somente a "identificação" das populações com as suas cidades poderá garantir a "singularidade e autenticidade cultural". Razão pela qual a Nova Agenda Urbana das Nações Unidas, refere que "as Cidades e assentamentos humanos para além da sua função social devem ser participativos, promovendo o engajamento cívico, criando sentimentos de pertença e apropriação entre os seus habitantes..." ${ }^{2}$.

\section{ENQUADRAMENTO REGIONAL}

Algarve

O Algarve, banhado a sul e poente pelo Atlântico, separado de Espanha pelo Rio Guadiana e do

${ }^{1}$ Recorrendo ao ensaio, partilhamos a definição de vitalidade urbana às cidades que têm a "capacidade de funcionar como nós centrais nos processos de convivialidade e de sociabilidade que são fulcrais na criação de reputação e legitimação nas actividades culturais" (p. 104).

2 HABITAT III - 3. a Conferência da ONU - Quito, Equador, outubro de 2016, In «http://habitatiii.dgterritorio.pt/?q=content/confer\%C3\%AAncia-habitat-iii» Consultado em 15.03.2018 


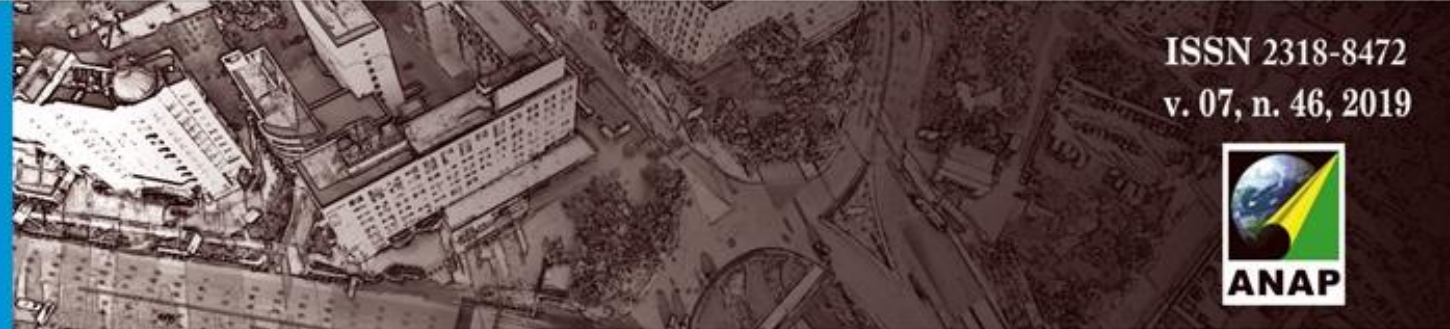

Revista Nacional de Gerenciamento de Cidades

Alentejo pelas ribeiras de Odeceixe e do Vascão e pelas serras de Monchique e do Caldeirão, assume-se como uma região bem distinta do restante território continental. Estende-se de Este a Oeste numa distância de $178 \mathrm{Km}$ e constitui-se numa estreita faixa de terreno (FEIO, 1983) com cerca de cinco mil quilômetros quadrados. Subdividido em duas partes, em longitude barlavento e sotavento, e em três, em latitude - litoral, barrocal e serra, atualmente é constituído por dezoito Municípios.

A análise que aqui se efetua não pretende ser uma narrativa histórica, mas apenas ser o olhar do estudioso da cidade a "deambular" pela história.

Se observarmos a história fundacional dos assentamentos urbanos verificamos que a ocupação do sul de Portugal ocorreu em duas linhas paralelas (Figura 1), uma junto à costa - cidades ribeirinhas ou portuárias - normalmente fundadas pelos fenícios ou cartagineses e outra linha mais interior, passando pelos pontos mais altos - cidades colinas - funcionando como a segunda linha defensiva do território.

Figura 1 - Casos de Estudo e Linhas de colonização do Algarve, Portugal

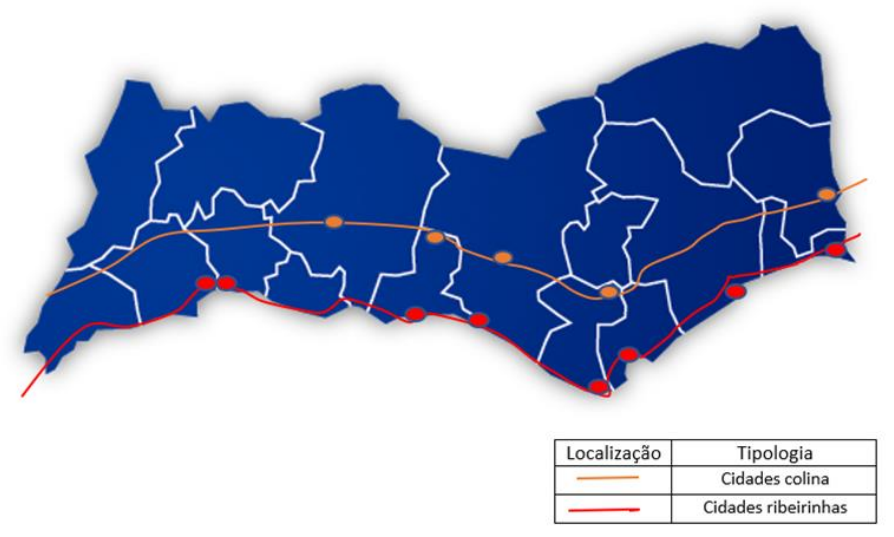

Fonte: Elaborado pelos autores

No período da ocupação romana, foi criada uma vasta rede viária, que permitiu a interligação territorial e funcional na província da Lusitânia, acentuando a complementaridade entre as cidades ribeirinhas e as cidades colinas na ocupação e defesa do território.

Durante as ocupações romana (séc II) e árabe (séc VIII a XII), a grande maioria dos aglomerados urbanos existentes foram "reutilizados", sem prejuízo de terem sido fundadas novas povoações, como é o caso de Loulé - Al-'Ulya' - fundada pelos árabes (PALMA, 2015).

A morfogênese dos núcleos urbanos esclarece que, por norma, a fundação seguia a regra da utilização da topografia para a abertura das vias e a "conformação" da malha urbana e respectivos quarteirões com o perímetro da muralha (no caso das cidades amuralhadas), cuja regularidade do limite geralmente se devia a dois fatores: construção na totalidade ou por trechos e topografia local.

O Algarve, pela sua localização mediterrânea e pela ocupação islâmica durante quatro séculos, possui muitas influências árabes, sendo um território físico, humano e cultural bastante peculiar no cenário português. 


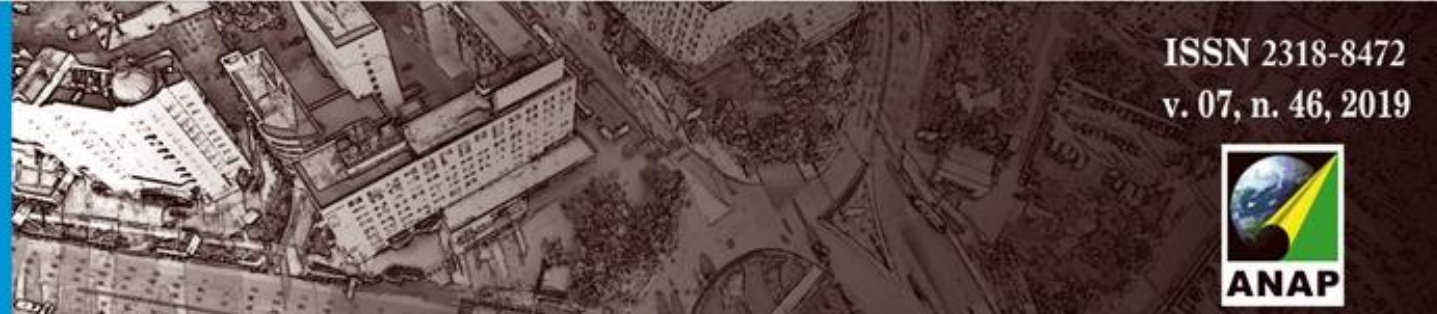

\section{Revista Nacional de}

Gerenciamento de Cidades

Em termos de atividades econômicas, durante muitos séculos esteve vocacionado para a agricultura de sequeiro no interior e a pesca no litoral, com as indústrias artesanais associadas à secagem de frutos, salga do peixe, doçaria regional, artesanato com empreita, entre outros. No entanto, na história mais recente, ocorreram dois contextos conjunturais assinaláveis que alteraram radicalmente o território. $O$ primeiro se deu com o incremento da indústria de conservas em inícios da Primeira Guerra Mundial (RODRIGUES, 2011), posto que as conservas eram enviadas para as tropas portuguesas e aliados, sendo Manuel Ramirez e Júdice Fialho os maiores empresários. Para fazer face à procura de mão-de-obra no Algarve, o trabalho nas fábricas era sobretudo realizado por mulheres e crianças. A população aumentou, agravando-se os problemas de habitação, higiene e salubridade, tendo havido alguns industriais que construíram casas para os trabalhadores junto às fábricas.

Em Portimão, grande centro conserveiro naquela ocasião, ainda subsiste uma dessas vilas operárias, denominada "comboio [trem] parado".

Com o fim da Primeira Guerra, houve um declínio na indústria de conservas, que, apesar de ter tido alguma recuperação durante a Segunda Guerra Mundial, nunca mais atingiu o mesmo fulgor, tendo acabado por fenecer, trazendo no seu bojo uma crise econômica considerável.

No entanto, com o advento do turismo, que surgiu a partir dos anos 1960, o Algarve voltou a ganhar estabilidade econômica, apesar dos graves problemas de ordenamento territorial daí advindos, devido ao crescimento desordenado e à ausência de políticas reguladoras eficazes.

O turismo de sol e praia, por um lado, acentuou a dicotomia litoral/ interior, e, por outro, favoreceu o desenvolvimento da indústria da construção civil, que cresceu sem regras, provocando a descaracterização de grande parte dos centros antigos das cidades ribeirinhas.

\section{CASOS DE ESTUDO}

Como refere Fernandes (2014), as cidades portuguesas na sua generalidade distribuem-se entre cidades ribeirinhas e cidades colinas. Como casos de estudo, selecionaram-se duas cidades com sistema defensivo envolvente (muralhas), uma no litoral do barlavento (cidade ribeirinha) e outra no interior do sotavento (cidade colina).

Evidentemente, por um lado, a própria localização geográfica define influenciadores distintos, e, por outro, as diferentes políticas urbanas determinarão diferenças entre as cidades. $O$ que se pretende nesta análise comparativa é demonstrar que a identificação das populações, sejam elas compostas por naturais ou residentes, independentemente do percurso histórico e evolutivo, será consequência da capacidade do poder local envolver a sociedade civil nas políticas urbanas, mantendo-se a "construção coletiva" das narrativas históricas, uma vez que a própria identidade urbana e memória coletiva são fruto de uma co-criação e até reinvenção coletiva (SILVA, 2017).

Diz-nos Halbwachs (1990) que:

A memória coletiva é um conjunto de lembranças construídas socialmente e referenciadas a um conjunto que está para além do indivíduo (...) e simultaneamente uma corrente de pensamento permanente, que se transforma e redefine continuadamente, porque apenas retém do passado aquilo que ainda está vivo ou é capaz de viver na consciência do grupo e que lhe interessa (Apud, RIBEIRO e 


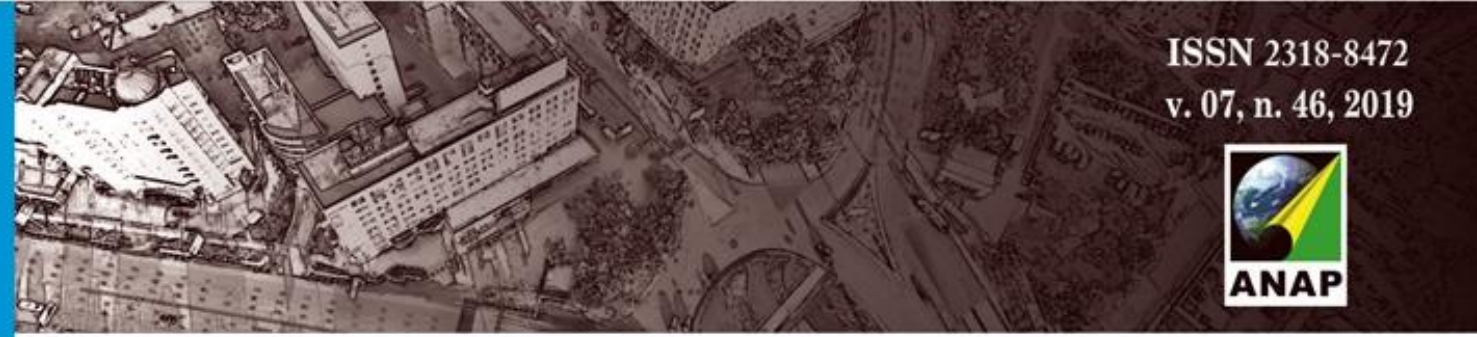

\section{Revista Nacional de} Gerenciamento de Cidades

Quando o território algarvio estava ocupado pelos árabes e Silves era a capital, Portimão era o porto de Silves (CARRAPIÇO et al, 1974), devido às suas excepcionais condições naturais. Com a reconquista cristã e o progressivo assoreamento do rio Arade, Portimão ganhou cada vez mais protagonismo, até que a Vila Nova de Portimão amuralhada surgiu no contexto do século XV, tendo como primeiro donatário Rui Afonso de Mello, porta-estandarte do Infante D. Henrique na Jornada de Tânger. Carrapiço, Palhinha e Brázio (1974) também referem que foi D. Afonso V $(1438-1481)$ quem ordenou a construção da muralha, cuja construção é citada tanto nas Cortes de Évora de 5 de Março de 1475, onde é pedida "a continuação do cerco de Villa Nova de Portimão", quanto nas Cortes de Montemor-o-Novo, a 9 de Fevereiro de 1477, e o seu término teria ocorrido por volta da primeira metade do século XVII.

Esse longo tempo de construção documentado parece ser comprovado na própria configuração da muralha, justificando a sua constituição em trechos descontínuos, conforme Figura 3.

Apesar de Carrapiço, Palhinha e Brázio (1974) referirem que a cerca de Portimão foi mandada executar no século XV por $D$. Afonso $V$, a sua tipologia se insere no âmbito dos núcleos urbanos medievais portugueses planejados e fortificados (séc. XIII-XIV), cuja fundação esteve ligada aos processos de reconquista e de repovoamento do território tomado aos mouros. Saliente-se que o terremoto de 1755, que tantos estragos causou em Lisboa, também foi avassalador no Algarve, tendo restado muito poucos edifícios anteriores ao século XVIII.

A Vila Nova de Portimão adquiriu o estatuto de cidade em 11 de dezembro de 1924 (após uma primeira tentativa do Marquês de Pombal, quando tentou criar dois bispados no Algarve, oportunidade perdida com a morte do Rei D. José I), por proposta do então Presidente da República, o portimonense Manuel Teixeira Gomes.

Figura 3 - Evolução Morfológica de Portimão
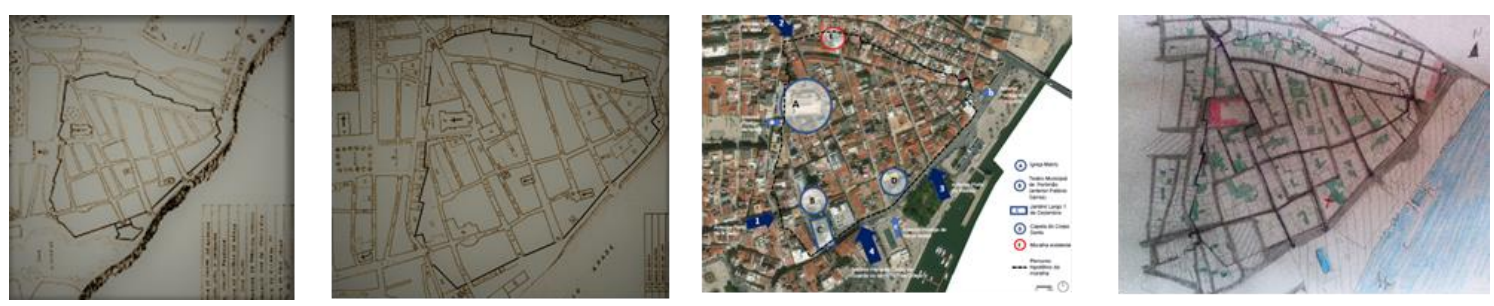

Fonte: A primeira imagem refere-se ao mapa de 1773 e o segundo de 1818 desenhados por Carrapiço, Palhinha e Brázio (1974). A terceira imagem é de autoria dos autores, na qual, sobre uma foto aérea, foram assinalados os elementos urbanos mais importantes, incluindo as portas e os postigos com base nas descrições históricas. A última imagem é um desenho à mão sobre uma forma urbana de autoria de Lucinda Caetano. ${ }^{4}$

Relativamente à muralha de Portimão, como se verifica na planta atual, foi completamente adossada às edificações passando a integrar e definir a forma urbana, excetuando nos trechos que foram demolidos - junto ao rio e na entrada da Igreja Matriz de Portimão.

A ampliação da ocupação urbana, conforme Figura 4, inicia-se a poente (no local de realização da feira), junto ao Postigo da Igreja, onde a posteriori foi construída a Igreja do Colégio dos

\footnotetext{
${ }^{4}$ Nesta composição não houve a intenção de manter a escala, mas mostrar a evolução urbana (ampliação ocupacional e dimensões/ subdivisões dos quarteirões e das parcelas).
} 


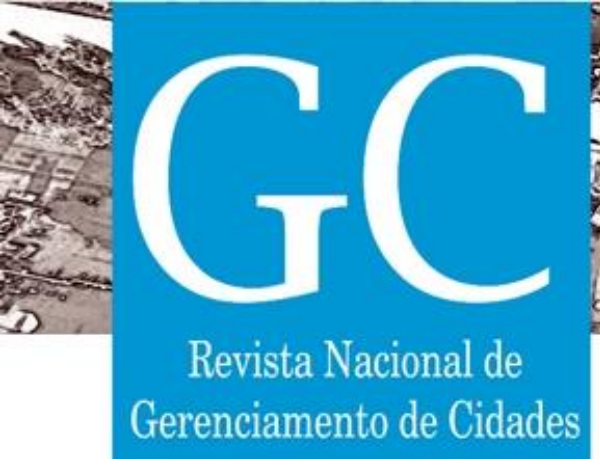

Figura 6 - Fotografa aérea de Portimão atual

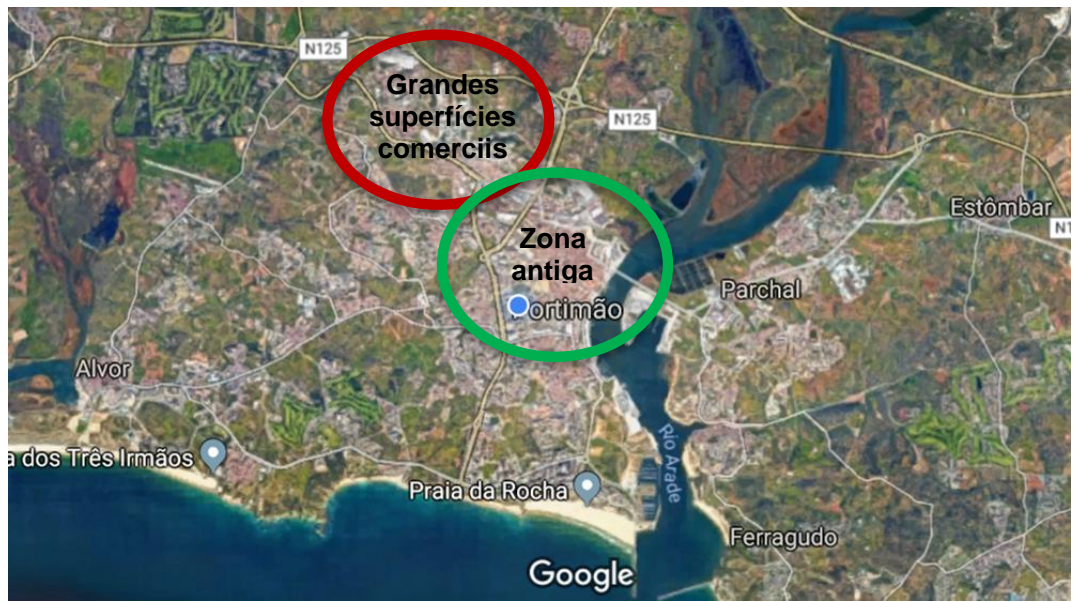

Fonte: In « https://www.google.pt/maps/@37.1398938,-8.5359062,7685m/data=!3m1!1e3», consultado em março 2018

No caso de Portimão, o poder político, a partir dos primeiros anos do século XXI, optou pela afirmação internacional da marca Portimão, com o recurso ao marketing territorial, à organização de megaeventos de nível internacional, com forte impacto midiático, e à construção de equipamentos culturais e esportivos de grandes dimensões, como o Autódromo Internacional do Algarve e o Pavilhão Arena. Neste contexto futurista, todos os projetos pareciam possíveis, e Portimão perfilava-se na cena regional como a capital do barlavento.

Entretanto, em 2013, o sonho caiu por terra, quando a Câmara Municipal de Portimão, para evitar a falência, solicitou um empréstimo de 132 milhões de euros para pagar dívidas em atraso, reconhecendo "grandes dificuldades" na tesouraria municipal, na sequência de uma polêmica na Comunicação Social envolvendo detenções e processos judiciais.

Se observarmos a distribuição funcional, à primeira vista parece desajustado que o centro antigo esteja devoluto e degradado, uma vez que o mesmo se encontra cercado de equipamentos e zonas de comércio local. No entanto, devido à sua proximidade com uma zona de grandes superfícies comerciais, há uma concorrência direta e "desleal" com o comércio tradicional na zona antiga, que carece de boa acessibilidade e estacionamento gratuito.

Neste momento, verifica-se que, salvo uma zona residencial a norte, a zona antiga sofre um processo acelerado de gentrificação, com edifícios degradados e devolutos, uma zona de comércio e serviços fragilizada, onde as atividades que ainda proliferam são o alojamento local do tipo "hostel" e restaurantes.

Parece-nos importante ressaltar que, em Portimão, as políticas urbanas estiveram sempre voltadas para o exterior, sem relação com a sociedade civil local ou com o Associativismo. No entanto, a crise financeira trouxe um aspecto favorável relativo à aproximação do Poder local ao associativismo, uma vez que passaram a ser as associações a realizar os eventos culturais. Nesse contexto, percebe-se que, se, por um lado, as atividades culturais passaram a ser feitas a custo zero para o Município, por outro permitiram às Associações ganhar visibilidade. 




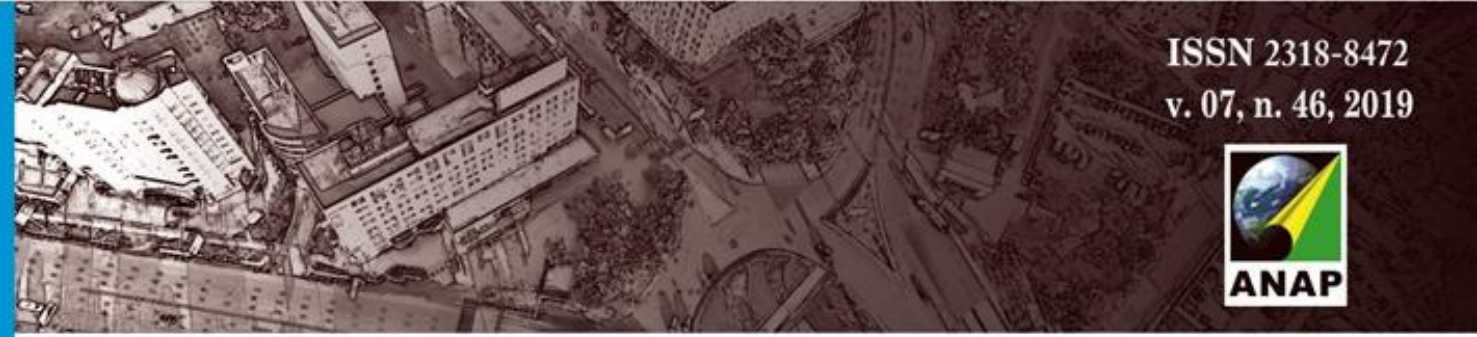

\section{Revista Nacional de} Gerenciamento de Cidades

Figura 9- Evolução urbana após 1974 e situação atual

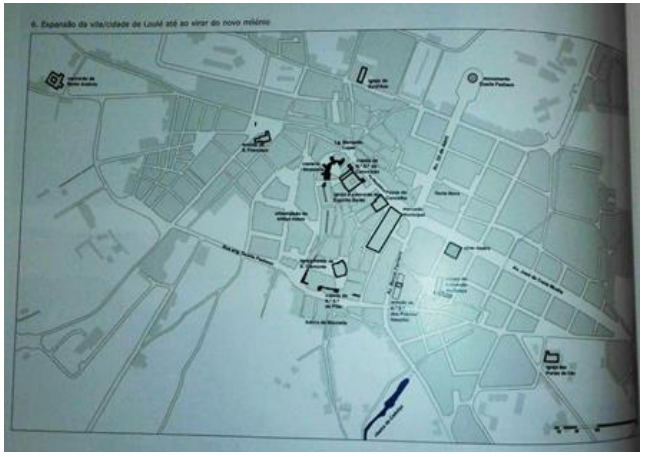

Fonte: A primeira imagem foi retirada de RAPOSO

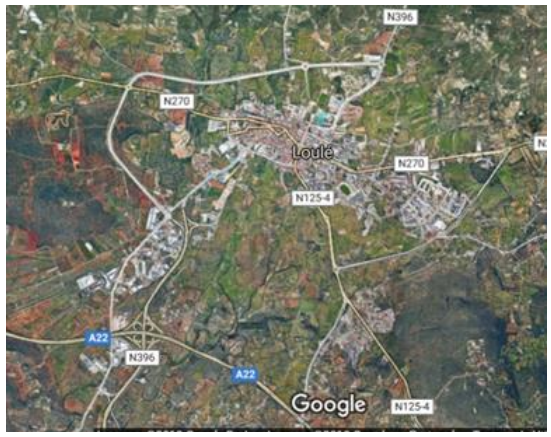
$(2007, \quad$ p. 34) e a segunda In
!3m1!1e3», consultado em março de 2018

A partir desse momento, verifica-se, à semelhança de Portimão, que em Loulé (apesar de se localizar no interior) se mantém o mesmo padrão da urbanização descontínua e fragmentada (Figura 9). No entanto, a localização no interior da cidade de Loulé determinou menor pressão turística/construtiva, mantendo-se uma população local coesa e próxima do poder local.

O aglomerado urbano de Loulé (elevado a cidade em 1 de fevereiro de 1988), sede do Município, usufrui da confortável situação financeira do Município devido, sobretudo, aos empreendimentos turísticos de luxo, nomeadamente, Vilamoura, Vale do Lobo e Quinta do Lago, com densidades construtivas baixas, dotados da "artificialidade" da típica construção algarvia "inventada" para ser o emblema da autenticidade regional.

Neste caso, como o território litoral já se encontrava "comprometido" com os empreendimentos turísticos, a especulação imobiliária restringiu-se ao aglomerado urbano situado no litoral - Quarteira -, permitindo a preservação do centro histórico de Loulé, ainda que, devido à sua localização, não tenha conseguido captar novos moradores e visitantes.

As políticas urbanas para Loulé a partir de 2003 se basearam na preservação do centro urbano antigo, na contenção da construção em altura e na proibição de implantação de grandes superfícies comerciais nas proximidades.

Por outro lado, a política cultural potenciou o centro antigo e divulgou a marca Loulé associada a festivais urbano - como MED (de música de todo o mundo) e Noite Branca -, colocando Loulé no circuito turístico cultural internacional. Simultaneamente, investiu-se na política de revitalização dos espaços públicos e privados da Câmara, inseridos no centro antigo junto com escavações arqueológicas. Para além disso, têm aplicado projetos potenciadores de "identidade", alguns deles advindos de associações locais, como a recuperação de profissões antigas e a captação de jovens aprendizes, ideia que surgiu numa atividade de cidadania promovida pela Casa de Cultura de Loulé.

Apesar de existirem muitas edificações degradadas ou devolutas, devido inclusive à não adaptação das estruturas antigas ao modo de vida atual, o centro antigo de Loulé mantém uma vitalidade razoável, estando em termos de atividades econômicas suportado pelo comércio local e pelos vários serviços públicos, espalhados pela zona antiga, cujo centro nevrálgico é o Mercado Municipal - que, apesar de remodelado, manteve o seu traçado original. 


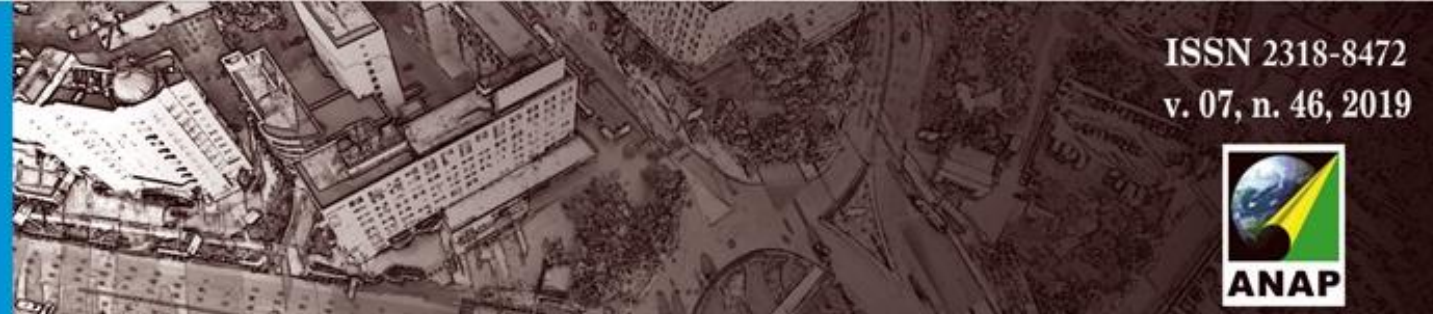

\section{Revista Nacional de}

Gerenciamento de Cidades

\section{ALGUMAS CONSIDERAÇÕES CONCLUSIVAS}

A narrativa histórico-evolutiva de Portimão e Loulé procurou desvelar algumas características indutoras de funções urbanas distintas, inerentes aos dois tipos morfológicos de cidades no contexto fundacional português - cidades ribeirinhas e cidades colinas - enquadradas numa região, com um carácter singular no panorama nacional.

Nesta linha de pensamento, o respeito pelo patrimônio cultural constituído pelos centros antigos, enquanto documento histórico de uma determinada cultura num arco temporal específico, será capaz de potenciar/recuperar a memória das cidades, e, portanto, a sua identidade, o seu "código genético", ou como afirma Sérgio Fernandes (2014, p. 5):

a observação do tecido urbano edificado no tempo longo onde estão depositados os valores da urbes, como um meio para superar as rupturas existentes, para procurar uma identidade estética da cidade.

Contudo, nas nossas sociedades do conhecimento, que permitem a informação instantânea de qualquer acontecimento na escala global, tem-se a percepção de que os "espaços de fluxos" 5 muitas vezes substituem os "espaços de lugares" ${ }^{\text {, }}$ no dizer de Castells, e onde os "não-lugares", de Marc Augé (SÁ, 2014), reproduzem-se anonimamente pelo mundo e assinalam a dicotomia entre cidade e urbano ${ }^{8}$, como argumenta Choay (2004).

Nesse "desligamento" identitário, cada vez mais se valorizam os centros antigos europeus (ou "históricos"), como repositórios de identidades e memórias urbanas e coletivas, e que pela sua própria forma urbana (compacta em oposição à urbanização extensiva) ${ }^{9}$, encontram-se plenos de urbanidade ${ }^{10}$, como salienta Françoise Choay (2004).

No entanto, esse aumento de interesse relativamente aos centros antigos, tão usual nas nossas sociedades de consumo, associa a noção de "cidade histórica" a "mercadoria cultural" (VAZ,

\footnotetext{
${ }^{5}$ De acordo com Castells (Apud SÁ, 2014) os espaços de fluxos são projetados para o mundo, mas sem raízes no lugar. Seria o oposto do que o autor denomina "espaços de lugares".

${ }^{6}$ Os "espaços de lugares "na aceção de Castells equivalem aos "lugares antropológicos" de Augé, onde a experiência dos indivíduos está vinculada aos espaços que eles percorrem e habitam, à sua cultura, à sua história. (Apud SÁ, 2014).

7 Os "não-lugares" descritos por Augé (2000, Apud SÁ, 2014) não têm como vocação o território, nem se vinculam a identidades ou relações simbólicas ou patrimoniais, mas pretendem facilitar a circulação (informação e consumo) à dimensão planetária. Como exemplos de "não-lugares" são considerados as grandes superfícies comerciais, as autoestradas e os aeroportos.

${ }^{8}$ Françoise Choay (2004) salienta a dicotomia entre cidade e urbano, ao avaliar que na cidade encontramos a junção entre urbes (suporte físico) e civitas (comunidade) enquanto o urbano apresenta "espaços construídos", cujo sistema operativo é válido em qualquer lugar, na cidade ou no campo. (T.A.).

${ }^{9}$ Como refere Cavaco (2014, p. 1) "A resposta canônica para os problemas da urbanização extensiva tem sido o retorno a um modelo de cidade compacta, como um tipo menos predatório e mais sustentável da forma urbana.".

${ }^{10}$ Considerando "Urbanidade" como o "ajuste recíproco de uma forma de tecido urbano e de uma forma de convivência" (T.A.). (CHOAY, 2004).
} 


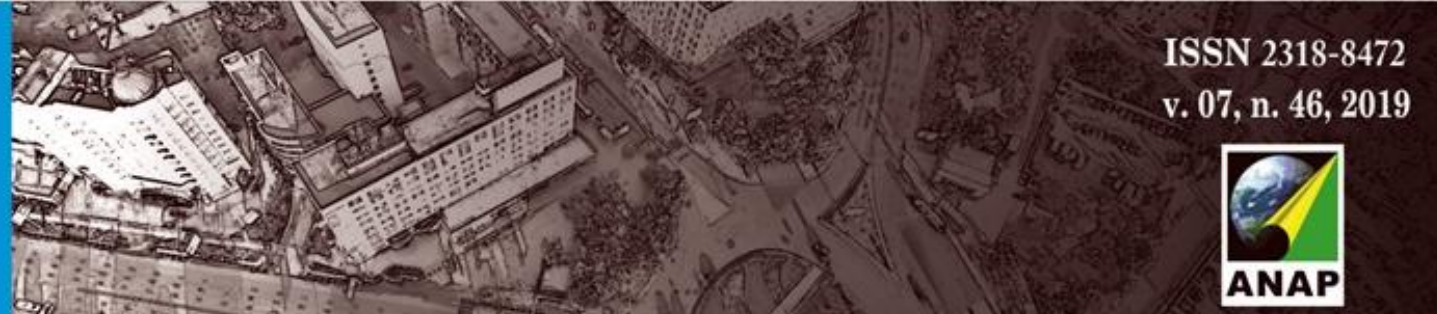

\section{Revista Nacional de}

Gerenciamento de Cidades

2004) $)^{11}$, sendo responsável em grande medida pela gentrificação e consequente descaracterização sociocultural nos processos de regeneração urbana. Essa gentrificação tanto pode ser ativa quanto passiva. Será ativa quando promovida pelas políticas urbanas, e passiva quando é a própria comunidade que se retira, por considerar que já não se sente identificada com o "sítio", ou por inadequação funcional com o modo de vida atual.

Pelo referido, pressente-se a relação entre forma urbana, urbanidade e identidade, tendo como refere Choay (2004), inclusive servido de inspiração a Camillo Sitte, que, aplicando conceitos estéticos à semelhança de Vitrúvio, publicou o livro intitulado "Construção das cidades segundo seus princípios artísticos" em 1889. Esse livro influenciou tanto estudiosos da cidade existente, como Patrick Geddes e Lewis Mumford, quanto planejadores das novas cidades, como Gustavo Giovannoni, que considerava que o "estudo do tecido dos centros urbanos históricos revela uma escala de proximidade que pode servir de princípio gerador e regulador".

Por outro lado, verifica-se que num mundo globalizado, onde identidade e autenticidade são fatores de valor na competitividade entre as cidades, são as políticas urbanas e o engajamento das comunidades que poderão fazer a diferença, conferindo vitalidade social sustentável aos núcleos urbanos, adaptando-se a novos usos e novos costumes.

Apesar das distinções históricas e conjunturais entre Portimão e Loulé, parece-nos claro que Portimão, devido à sua localização geográfica, próximo do litoral, teria mais oportunidade de ter o seu centro antigo atrativo para o turismo cultural e ser um elemento diferenciador em termos de competitividade territorial. Contudo, a materialização das políticas urbanas assumidas, e em especial, o seu distanciamento das populações locais, tornaram o centro antigo de Portimão um dos exemplos mais profundos de desenraizamento cultural e social.

Esta conclusão é decorrente de uma análise, que recorreu a vários métodos (CAETANO, No prelo; CAETANO et al, 2018a , 2018b, 2018c; CAETANO, 2017), nomeadamente: observação direta dos casos de estudo; entrevistas semiestruturadas a atores chaves das comunidades das duas cidades - técnicos dos Municípios, líderes das Associações Locais, profissionais liberais e lojistas - e com o método random-route - a pessoas comuns que encontrávamos nas ruas dos centros antigos -; análise cartográfica evolutiva; verificação da vitalidade urbana através da contagem de estabelecimentos de comércio fechados, de passantes nas ruas e das tipologias e diversidade de atividades de comércio/ serviços e criativas existentes.

No entanto, por considerarmos que a análise do investigador deverá, sempre que possível, ser avaliada através do confronto com o "sentir e o pensar" das populações, fomos ouvir atoreschaves das duas cidades, através de inquéritos por questionário. No caso de Portimão, foram preenchidos trinta e nove questionários, distribuídos em dois eventos públicos, um encontro sobre "O Impacto do Voluntariado para o Desenvolvimento Económico e Social Local", realizada pela Associação Teia de Impulsos, e a Feira de Natal, realizada pela Associação Contramaré, ambas em dezembro de 2018. No caso de Loulé, foram preenchidos vinte e quatro questionários, distribuídos aos funcionários da Administração Pública do Município via email. Cada questionários foi estruturado em três partes distintas: CARACTERIZAÇÃO DOS INQUIRIDOS,

${ }^{11}$ Lilian Vaz (2004) ao analisar os processos de regeneração dos centros antigos afirma que "Duas tendências, no entanto, parecem recorrentes: a gentrificação - expulsão da população e atividades locais, devido à valorização dos imóveis da área, e a espetacularização da cidade (no sentido atribuído por Debord), a que todos assistem, estupefatos, numa passividade consumista, alienante e sem participação." (p. 7). 




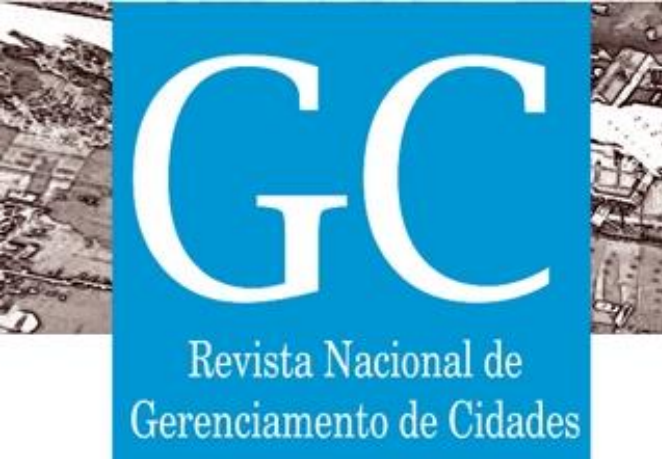

PALMA, J. F. M. da. O Desenvolvimento Urbano de Loulé. Do período medieval ao fim da época Moderna. Mestrado em História do Algarve - Universidade do Algarve, Faro, 2015.

RAPOSO, I. Guia da Reabilitação e Construção. Cidade de Loulé. Loulé: Câmara Municipal de Loulé, s/d.

RIBEIRO, M. do C. e MELO, A. S. “A materialização dos poderes no espaço como expressão da memória e identidade urbana medieval". Revista Medievalista online. online Número 12 | Julho - Dezembro 2012, [Consultado 15.03.2018]. Disponível em

«http://www2.fcsh.unl.pt/iem/medievalista/MEDIEVALISTA12\melo_ribeiro1207.html».

RIBEIRO, M. do C. e MELO, A. S.. O papel dos sistemas defensivos na formação dos tecidos urbanos (séculos XIII XVII). In Evolução da paisagem urbana transformação morfológica dos tecidos históricos. Braga: Universidade Nova de Lisboa, 2013, pp. 183-222.

RODRIGUES, J. V. A indústria de conservas de peixe no Algarve (1865-1945), 1997; Ferreira, Álvaro Joaquim Fernandes - As conservas enlatadas na alimentação das tropas em campanha, 1949; Ramirez, Memórias de cinco gerações, Edição da empresa, 2011.

SÁ,T. "Lugares e não lugares em Marc Augé". Tempo Social. Revista de Sociologia da USP. v. 26, n. 2, 2014, pp. 209229.

SILVA, J. M. M. F. S. A invenção do património urbano. Processos de produção dos lugares patrimoniais em Portugal. Tese doutoral - Faculdade de Arquitetura. Universidade de Lisboa, Lisboa, 2017.

VAZ, L.F. Planos e projetos de regeneração cultural: notas sobre uma tendência urbanística recente. Anais: Seminário de História da Cidade e do Urbanismo, Sessão Temática: Imagens, Práticas Sociais e Representações 8. 2004 